\title{
Health care utilization by veterans prescribed chronic opioids
}

\author{
Cynthia Kay ${ }^{1,2}$ \\ Erica Wozniak ${ }^{2}$ \\ Alice Ching' \\ Joanne Bernstein' \\ 'Clement J Zablocki - Department of \\ Medicine, ${ }^{2}$ Center for Patient Care \\ and Outcomes Research, Medical \\ College of Wisconsin, Milwaukee, WI, \\ USA
}

Correspondence: Cynthia Kay Medical College of Wisconsin, 870I W Watertown Plank Road (CAP), Milwaukee WI 53226, USA Email ckay@mcw.edu
This article was published in the following Dove Press journal: Journal of Pain Research

\begin{abstract}
Purpose: Ambulatory resources such as telephone calls, secure messages, nurse visits, and telephone triage are vital to the management of patients on chronic opioid therapy (COT). They are also often overlooked as health care services and yet to be broadly studied. The aim of the present study was to describe the Veterans Affairs (VA) health care utilization by patients based on COT, type, and amount of opioids prescribed.
\end{abstract}

Patients and methods: A retrospective chart review was done on 617 patients on COT at a VA primary care clinic. Instances of health care utilization (emergency department visits [EDVs], hospitalizations, clinic visits, telephone triage calls, telephone calls/secure messages/ nurse visits) were obtained.

Results: Patients were likely to have more telephone calls, secure messages, or nurse visits if they were prescribed a schedule II opioid or if they were on more than one opioid. Model-based results found that patients on COT were more likely to have EDVs, telephone triage calls, and clinic contact compared to patients who were not on chronic opioids.

Conclusion: The results are despite having a Patient Aligned Care Team, which is the VA's patient-centered medical home. This suggests that reducing health care utilization for patients on COT may not be possible with just a primary care involvement.

Keywords: opioids, Veterans Affairs, primary care, chronic pain

\section{Introduction}

The Veterans Health Administration (VHA) has a vested interest in the management of chronic pain for many reasons. For one, chronic pain is prevalent, affecting 50 million Americans in 2012. ${ }^{1}$ Furthermore, past works have shown that the veteran population tends to have more medical conditions and worse health compared to the non-veteran population. ${ }^{2,3}$ Specifically, chronic pain and mental health disorders are more prevalent within the veteran population with the former having estimated rates twice those of the civilian population. ${ }^{4-7}$ Given the association between mental health disorder and chronic pain, there is often an added layer of complexity with regard to chronic pain management. ${ }^{8-10}$

The Patient Aligned Care Team (PACT) is the VHA's patient-centered medical home (PCMH). Each PACT teamlet consists of the primary care provider, nurse, clinical associate (health technician, licensed practical nurse), and administrative associate. ${ }^{11}$ Teamlets share a clinic pharmacist, social worker, and dietitian. ${ }^{12}$ Some of the PACT goals include providing access to primary care through a variety of methods and improving health care outcomes and costs. Studies examining the effectiveness of the PACT have shown fewer emergency department visits (EDVs) and hospitalizations 
with a coinciding increase in primary care visits and telephone encounters. ${ }^{13,14}$ While mental health and substance use disorders were sometimes included in these studies, the presence of chronic pain has not been taken into account.

Prior studies have also shown that there is an association between chronic pain and increased health care utilization. ${ }^{15-17}$ Many of these studies focused on common services, such as EDVs, hospitalizations, specialty cares, and prescription drugs. Little is known about the use of health care resources such as telephone calls and secure messages, which are not often mentioned or studied. These resources are integral parts of ambulatory medicine, especially primary care.

The objectives of this study were to describe Veterans Affairs (VA) health care utilization by patients based on chronic opioid therapy (COT) and the type and amount of opioids prescribed. It is hypothesized that: 1) patients on COT utilize more health care resources compared to those not on opioids; and 2) patients prescribed schedule II or more than one opioids have greater health care utilization compared with those on a lower schedule or a single opioid. We also examined the potential independent predictors of health care utilization in a multiple regression model.

\section{Methods}

\section{Study design and setting}

This was a retrospective chart review of primary care patients at the VA Medical Center in Milwaukee, WI, USA. Medical records were extracted from the Computerized Patient Record System (CPRS), the electronic medical record (EMR) utilized by the VHA system. This study met the criteria for minimal risk, and informed consent was waived. It was approved by the Zablocki VA Institutional Review Board.

\section{Study sample}

Potential patients were identified through the VA Informatics and Computing Infrastructure (VINCI). Patients were at least 18 years old and prescribed opioids chronically. COT was defined as at least three monthly prescriptions in the 12-month period between April 1, 2014 and April 1, 2015. The prescriptions did not have to be consecutive. This was based on the National Institutes of Health definition and criteria from prior studies. ${ }^{18-20}$

Patients with active cancer, on hospice, prescribed an opioid within 6 months of surgery, have not visited the clinic at least once during the established time frame, who died during the study period, or who no longer received primary care at this VA in the same time span were excluded. Charts were reviewed to ensure that the patients met the inclusion criteria. Patients on COT were matched by age and gender to controls who were not prescribed opioids.

\section{Data collection}

Patient demographics (age, gender, and race), diagnoses, provider characteristics (physician and advanced practitioner), mental health provider, service connection, and health care utilization counts (EDVs, hospitalizations, clinic visits, telephone triage calls, and telephone calls/ secure messages) were obtained through a manual review of the charts by the study team members ( $\mathrm{AC}$ and $\mathrm{CK}$ ). For patients on COT, the opioid regimen at the end of the study period was collected. Data were entered and stored in REDCap (Research Electronic Data Capture), which is a secure, web-based application designed to support data capture for research studies. $^{21}$

\section{State policy}

At the time of this study, Wisconsin did not require a minimum number of clinic visits for patients on COT and did not require providers to access the state's prescription drug monitoring program (PDMP) prior to prescribing opioids.

\section{Measures}

The examined measures of health care utilization included counts of EDVs, hospitalizations, primary care visits, telephone triage calls, telephone calls or secure messages, and nurse visits. Telephone triage is the VA's answering service. It is a 24-hour advice line staffed by nurses. Hospital discharge follow-up calls were not included as these are done per protocol.

Instances of each utilization variable were counted manually through chart review. Telephone calls, secure messages, and nurse visits were combined into a single measure as these represent methods to contact and communicate with providers or the PACT team. At this specific VA, patients may request to be seen by their PACT nurse at any time during the workday.

The morphine equivalent dose (MED) was calculated for each patient on long-term opioids. The Oregon Health \& Science University calculator was used to convert each patient's opioid regimen to a daily morphine milligram equivalent. ${ }^{22}$ The calculator's conversion factor's have been used in previous studies. ${ }^{23,24}$

\section{Analysis}

Demographic and clinical characteristics were compared between the COT and the non-opioid groups using chi-squared and independent samples $t$-tests for categorical and continuous variables, respectively. Descriptive statistics and bivariate 
analyses (chi-squared or Fisher's exact tests, where appropriate) were used to compare instances of health care utilization as counts by opioid status. Logistic regression was used to jointly assess the predictors of each health care utilization outcome, with hospitalizations and telephone triage calls (any vs none) as binary outcomes and $\operatorname{EDVs}(0,1,2+)$, office visits $(1,2-3,4+)$, and nurse visits/messages $(0-2,3-5,6+)$ as ordinal outcomes. Adjacent categories of the ordinal outcomes were pooled where cell sizes were small or the mean of the chronic pain indicator was similar across categories. Stepwise variable selection was used on 50 bootstrap sample replicates of a complete list of variables collected by chart review, including demographic, pain characteristic, diagnosis, and prescription information. The stepwise model was chosen to build parsimonious lists of independent predictors for each model since a large number of diagnosis, prescription, and demographic indicators were collected. Significant differences were observed between the pain and the non-pain groups for many of these indicators when calculating bivariate statistics. Due to the large number of potential predictors, stepwise selection was an effective method to reduce the models. Furthermore, resampling methods were used in model selection to lessen the effect of some of the drawbacks known to be associated with stepwise selection methods, such as the inclusion of noise variables and potential exclusion of authentic predictors. Variables were retained in each bootstrap sample using a significance cutoff of 0.2 . The final model included only those that were retained in at least $20(40 \%)$ bootstrap samples. From these models, odds ratios and corresponding predicted probabilities for each outcome were calculated to examine the effect of COT on utilization, controlling for relevant covariates, such as age, gender, and the presence of psychiatric disorders. Statistical significance was set at $P<0.05$.

\section{Results}

Initial screening through VINCI yielded 2,484 patients. The first 635 patients who met the inclusion criteria were included to meet statistical power requirements. These patients were those who were prescribed opioids chronically. The mean age of the patients on COT was 62 years (SD 12.6) and 625 $(98.4 \%)$ were male. The majority of patients on COT was white $(n=443,69.7 \%)$ and had a psychiatric diagnosis $(n=451$, $71.0 \%$ ). Overall characteristics of patients on COT compared with patients not on opioids are presented in Table 1.

\section{COT versus no opioid}

Patients on COT were more likely to have any psychiatric diagnosis, depression, anxiety, a mental health provider/
Table I Patient characteristics by chronic opioid therapy

\begin{tabular}{|c|c|c|c|}
\hline & $\begin{array}{l}\text { Non-opioid } \\
\text { group } \\
(\mathrm{N}=565)\end{array}$ & $\begin{array}{l}\text { Opioid } \\
\text { group } \\
(\mathrm{N}=617)\end{array}$ & $P$-value \\
\hline Age, mean (SD) & $62.5(12.5)$ & $61.9(12.6)$ & 0.44 \\
\hline \multicolumn{4}{|l|}{ Race } \\
\hline White & $369(65.3 \%)$ & $430(69.7 \%)$ & 0.12 \\
\hline \multicolumn{4}{|l|}{ Gender } \\
\hline Male & $558(98.8 \%)$ & 607 (98.4\%) & 0.76 \\
\hline \multicolumn{4}{|l|}{ Provider type } \\
\hline Physician & 314 (55.6\%) & $354(57.4 \%)$ & 0.57 \\
\hline Mental health team & I5I (26.7\%) & $280(45.5 \%)$ & $<0.001$ \\
\hline Psychiatric diagnosis & 275 (48.7\%) & 443 (7I.8\%) & $<0.001$ \\
\hline Depression & $122(21.6 \%)$ & $262(42.5 \%)$ & $<0.001$ \\
\hline Diabetes & $189(33.5 \%)$ & $204(33.1 \%)$ & 0.94 \\
\hline Anxiety & $50(8.8 \%)$ & $81(13.1 \%)$ & 0.02 \\
\hline PTSD & 99 (17.5\%) & $135(21.9 \%)$ & 0.06 \\
\hline Hypertension & $383(67.8 \%)$ & $436(70.7 \%)$ & 0.31 \\
\hline CKD/ESRD & $44(7.8 \%)$ & 68 (1 I.0\%) & 0.07 \\
\hline COPD/asthma & 81 (14.3\%) & $116(18.8 \%)$ & 0.05 \\
\hline $\mathrm{CAD} / \mathrm{CHF}$ & $116(20.5 \%)$ & $143(23.2 \%)$ & 0.30 \\
\hline Neuropathy & $53(9.4 \%)$ & 77 (I2.5\%) & 0.11 \\
\hline Obesity & 227 (40.2\%) & $24 I(39.1 \%)$ & 0.74 \\
\hline Arthritis/spinal stenosis & $133(23.5 \%)$ & $311(50.4 \%)$ & $<0.001$ \\
\hline $\begin{array}{l}\text { History of substance use } \\
\text { disorder }\end{array}$ & 68 (I2.0\%) & II2 (I8.2\%) & 0.004 \\
\hline Tobacco use & $|2|(2 \mid .4 \%)$ & $204(33.1 \%)$ & $<0.001$ \\
\hline Service connection & $259(45.8 \%)$ & $366(59.3 \%)$ & $<0.001$ \\
\hline
\end{tabular}

Abbreviations: PTSD, post-traumatic stress disorder; CKD, chronic kidney disease; ESRD, end-stage renal disease; COPD, chronic obstructive pulmonary disease; $C A D$, coronary artery disease; $C H F$, congestive heart failure.

team, arthritis/spinal stenosis, tobacco use, and service connection than patients not on opioids (all $P<0.05$ ). Patients on COT were more likely to have a history of substance abuse $(P=0.004)$. Substance abuse, as defined by the World Health Organization, includes the abuse of alcohol or any illicit drugs. ${ }^{25}$ There were no significant differences between groups for the presence of post-traumatic stress disorder, diabetes, hypertension, or coronary artery disease (CAD)/ congestive heart failure (CHF) (Table 1). Patients prescribed chronic opioids had more EDVs, clinic visits, telephone triage encounters, telephone calls/secure message/nurse visits (all $P<0.001)$, and hospitalizations $(P=0.003)$ compared with patients not prescribed opioids (Table 2).

\section{MED}

All opioids were included in the determination of each patient's total daily MED if they were on the patient's medication list as of April 1, 2015. Two MED groups (<50 mg vs $>50 \mathrm{mg}$ ) were formed based on the 2016 Centers for Disease Control and Prevention (CDC)'s opioid guideline. ${ }^{26}$ Most patients had a total daily MED of $<50 \mathrm{mg}(\mathrm{n}=353,64.7 \%)$. 
No significant differences were found in any of the health care utilization measures based on MED.

\section{Controlled medication schedule}

Schedule III and IV controlled medications were combined into a single category given the relatively small numbers of each individually. Patients on schedule II medications were

Table 2 Health care utilization by chronic pain

\begin{tabular}{|c|c|c|c|}
\hline & $\begin{array}{l}\text { Non-pain group } \\
(N=565)\end{array}$ & $\begin{array}{l}\text { Pain group } \\
(N=6 \mid 7)\end{array}$ & $P$-value \\
\hline \multicolumn{4}{|l|}{ ED visits } \\
\hline 0 & 405 (71.7\%) & $340(55.1 \%)$ & $<0.001$ \\
\hline I & $89(15.8 \%)$ & 114 (18.5\%) & \\
\hline $2+$ & 71 (12.6\%) & $163(26.4 \%)$ & \\
\hline \multicolumn{4}{|l|}{ Hospitalizations } \\
\hline 0 & 493 (87.3\%) & 495 (80.2\%) & 0.001 \\
\hline $1+$ & $72(12.7 \%)$ & $122(19.8 \%)$ & \\
\hline \multicolumn{4}{|l|}{ Clinic visits } \\
\hline 1 & $170(30.1 \%)$ & $|3|(2 \mid .2 \%)$ & $<0.001$ \\
\hline $2-3$ & $319(56.5 \%)$ & $347(56.2 \%)$ & \\
\hline $4+$ & $76(13.5 \%)$ & $139(22.5 \%)$ & \\
\hline \multicolumn{4}{|l|}{ Telephone triage } \\
\hline 0 & 442 (78.2\%) & $420(68.1 \%)$ & $<0.001$ \\
\hline $1+$ & $123(21.8 \%)$ & $197(31.9 \%)$ & \\
\hline \multicolumn{4}{|l|}{ Telephone/secure } \\
\hline message/nurse visit & $381(67.4 \%)$ & $322(52.2 \%)$ & $<0.001$ \\
\hline $0-2$ & III (19.7\%) & $160(25.9 \%)$ & \\
\hline $3-5$ & 73 (I2.9\%) & $\mid 35$ (2|.9\%) & \\
\hline $6+$ & & & \\
\hline
\end{tabular}

Abbreviation: ED, emergency department. more likely to have a higher number of telephone calls, secure messages, or nurse visits in a year $(P=0.001)$ compared with patients on schedule III or IV medications. There were no significant differences in the other health care utilization measures (Table 3).

\section{Number of opioids}

The majority of patients on COT were prescribed a single opioid $(n=477,87 \%)$. Patients prescribed more than one opioid had more telephone calls, secure messages, or nurse visits $(P=0.03)$. There were no significant differences in total EDVs, hospitalizations, telephone triage calls, and clinic visits (Table 3).

\section{Logistic regression - predictors of utilization}

Model-based results show that controlling for relevant demographic and clinical characteristics, patients on COT were more likely to have a higher number of EDVs than non-opioid control patients, with an adjusted common odds ratio of 1.9 (95\% CI 1.4-2.4). Similarly, patients on COT were more likely to have an increased number of telephone triage encounters (adjusted common odds ratio 1.4 [95\% CI 1.0-1.9]) as well as telephone calls, secure messages, or nurse visits (adjusted common odds ratio 1.6 [95\% CI 1.2-2.0]) (Table 4). After adjusting for demographic indicators, diagnoses, and other clinical characteristics, patients on

Table 3 Health care utilization by schedule and number of opioids

\begin{tabular}{|c|c|c|c|c|c|c|}
\hline & \multicolumn{3}{|c|}{ Opioid schedule $(N=546)^{a}$} & \multicolumn{3}{|c|}{ Number of opioids $(\mathrm{N}=546)^{b}$} \\
\hline & $\begin{array}{l}\text { II } \\
(\mathrm{N}=320)\end{array}$ & $\begin{array}{l}\text { III or IV } \\
(\mathrm{N}=226)\end{array}$ & $P$-value & $\begin{array}{l}\mathrm{I} \\
(\mathrm{N}=477)\end{array}$ & $\begin{array}{l}\text { II or III } \\
(\mathrm{N}=69)\end{array}$ & $P$-value \\
\hline \multicolumn{7}{|c|}{ ED visits } \\
\hline 0 & $|8|(56.6 \%)$ & $|3|(58.0 \%)$ & 0.92 & $266(55.8 \%)$ & $46(66.7 \%)$ & 0.22 \\
\hline I & $59(18.4 \%)$ & $42(18.6 \%)$ & & $92(19.3 \%)$ & $9(13.0 \%)$ & \\
\hline $2+$ & $80(25.0 \%)$ & $53(23.5 \%)$ & & $119(25.0 \%)$ & $14(20.3 \%)$ & \\
\hline \multicolumn{7}{|c|}{ Hospitalizations } \\
\hline$\geq 1$ & $69(21.6 \%)$ & $36(15.9 \%)$ & 0.13 & $98(20.6 \%)$ & $7(10.1 \%)$ & 0.06 \\
\hline \multicolumn{7}{|c|}{ Clinic visits } \\
\hline 1 & $62(19.4 \%)$ & $55(24.3 \%)$ & 0.29 & $103(21.6 \%)$ & 14 (20.3\%) & 0.95 \\
\hline $2-3$ & $185(58.0 \%)$ & $129(57.1 \%)$ & & $273(57.4 \%)$ & $4 \mathrm{I}(59.4 \%)$ & \\
\hline $4+$ & $72(22.6 \%)$ & $42(18.6 \%)$ & & $100(21.0 \%)$ & 14 (20.3\%) & \\
\hline \multicolumn{7}{|c|}{ Phone triage } \\
\hline$\geq 1$ & $101(31.6 \%)$ & $64(28.4 \%)$ & 0.49 & $190(31.2 \%)$ & $53(33.3 \%)$ & 0.68 \\
\hline \multicolumn{7}{|c|}{ Messages/nurse visits ${ }^{c}$} \\
\hline $0-2$ & 158 (49.5\%) & $138(61.1 \%)$ & 0.001 & $26 \mid(54.8 \%)$ & 35 (50.7\%) & 0.03 \\
\hline $3-5$ & 79 (24.8\%) & $58(25.7 \%)$ & & 125 (26.3\%) & 12 (I7.4\%) & \\
\hline $6+$ & $82(25.7 \%)$ & 30 (13.3\%) & & 90 (I8.9\%) & 22 (31.9\%) & \\
\hline
\end{tabular}

Notes: ${ }^{2}$ Subset of pain cohort with schedule information available. ${ }^{b}$ Subset of pain cohort with available information on number of opioids prescribed. Includes telephone calls, secure messages, and nurse visits.

Abbreviation: ED, emergency department. 
Table 4 Model-adjusted odds of health care utilization for pain versus non-pain patients

\begin{tabular}{llll}
\hline & Adjusted OR $^{\mathbf{a}}$ & $\mathbf{9 5 \%} \mathbf{~ C l}$ & P-value \\
\hline ED visits $^{\mathrm{b}}$ & 1.9 & $1.4-2.4$ & $<0.00 \mathrm{I}$ \\
Hospitalizations $^{\mathrm{c}}$ & 1.3 & $0.9-1.9$ & $0.1 \mathrm{I}$ \\
Clinic visits $^{\mathrm{d}}$ & $\mathrm{I} .2$ & $0.9-1.6$ & 0.15 \\
Telephone triage $^{\mathrm{c}}$ & $\mathrm{I} .4$ & $1.0-1.9$ & 0.03 \\
Messages $^{\mathrm{e}}$ & $\mathrm{I} .6$ & $1.2-2.0$ & $<0.00 \mathrm{I}$ \\
\hline
\end{tabular}

Notes: a Models were adjusted by applying a stepwise model selection process to the following patient characteristics: age; race; provider (advanced practitioner vs physician); psychiatric diagnosis; depression; diabetes; hypertension; cardiac, renal, and pulmonary disease; neuropathy; obesity; tobacco use or substance use disorder arthritis; service connection; and nonsteroidal anti-inflammatory, antiepileptic,

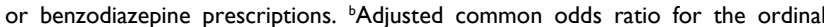
outcome of 0,1 , or $2+$ visits. 'Adjusted odds ratio given any vs none as binary outcome. ${ }^{\mathrm{d}}$ Adjusted common odds ratio for the ordinal outcome of I, 2-3, 4+ visits. eAdjusted common odds ratio for the ordinal outcome of $0-2,3-5$, or $6+$ telephone calls, secure message contacts, or nurse visits.

Abbreviation: ED, emergency department.

COT were not found to have more hospitalizations or clinic visits compared to patients not on opioids. The full models are provided in Tables S1-S5.

\section{Discussion}

As with prior studies, we found numerous differences in characteristics of patients on COT and those not on opioids. However, in our study, there were no significant differences in the proportion of patients with diabetes, $\mathrm{CAD} / \mathrm{CHF}$, or hypertension between the opioid and non-opioid groups. This contrasts with previous studies. ${ }^{27,28}$ Beehler et al focused on veterans with musculoskeletal pain. ${ }^{27}$ Their population was younger, with an average age of 56 years, compared to our study's average age of 62 years. ${ }^{27}$ The study by Kay et al focused on a civilian population, which could be considered to have fewer comorbidities. ${ }^{28}$

The main focus of our study remains consistent with previous works that demonstrated higher utilization by patients on chronic opioids. ${ }^{27,28}$ To our knowledge, this is the first study to examine the utilization of health care resources not easily measured by patients on COT at a VA and in a PACT.

The CDC-recommended morphine equivalent dose is lower than previous guidelines, based on studies that showed increased adverse risks with higher doses. While this study did not examine the adverse outcomes, it did not find any significant difference in health care utilization by MED.

Similar to the Kay et al study, patients on schedule II opioids were more likely to have a higher number of telephone calls, secure messages, or nurse visits compared to those on lower scheduled opioids. ${ }^{28}$ However, unlike that study, patients on more than one opioid also had more telephone calls, secure messages, and nurse visits. It is possible that patients who were prescribed stronger or more opioids have pain severity greater than those on less potent opioids or those who were prescribed just one. This may translate to more contact with their provider and PACT team for advice and recommendations.

The VHA started implementation of the PACT in 2010, and it is now fully functional across all VHAs. Past studies have demonstrated PACT effectiveness in decreasing utilization of health care resources, such as EDVs and hospitalizations but did not take chronic pain or oft-overlooked primary care resources into account. ${ }^{14,29}$

In our study, despite being managed by a PACT, patients on COT had significantly more EDVs, telephone triage, nurse visits, telephone calls, and secure messages compared to patients not on opioids. However, unlike a previous study, ${ }^{28}$ patients on COT did not have more hospitalizations or more clinic visits compared to patients without opioids, after adjusting for relevant demographic and clinical characteristics.

The PACT model allows patients to have greater access to their clinic nurse and provider. This might translate to more contact through telephone calls, secure messages, and nurse visits, as seen in our results. The increased utilization for certain services may simply be a fundamental consequence of the model itself. Correspondingly, these alternative methods for contact may also explain why there were not more clinic visits as noted in other studies.

As states and new laws target safe opioid practices to curb the opioid epidemic, a team-based approach seems most reasonably equipped to be successful. The PCMH or PACT model is considered the way to provide ideal primary care. While many aspects of chronic care management are implemented within the PCMH model, whether chronic pain can or should be managed the same way as other chronic diseases remains unclear. It may be naïve to assume that one model can be effectively used for the management of all chronic diseases.

Also, it may be that cost effective and appropriate health care utilization for the management of chronic pain is beyond the realm of care teams. A top-down approach, starting with national or state policies might be necessary. Florida, for example, demonstrated a decline in both prescription drug death and prescribing rates with the establishment of laws that targeted pill mills and made reporting to the state's PDMP mandatory. ${ }^{30,31}$

Multidisciplinary and interdisciplinary pain management programs have been shown to be beneficial for chronic pain. ${ }^{32,33}$ These programs offer a collaborative approach from providers of various disciplines who work together to address 
a common issue. Unfortunately, there are major barriers to the creation of these pain programs. Multi- and interdisciplinary programs require a significant amount of time, collaboration across fields, and infrastructure that may be difficult to acquire for most practices. Furthermore, these programs are not often covered by third-party payers.

\section{Limitations}

There are several limitations to this study. First, this was a retrospective chart review of a single VA medical center. Whether the population at this center can be generalizable to other VA centers or community clinics is uncertain. Second, we did not attempt to determine the reasons for each health care utilization count or limit them to those related only to pain. Along the same lines, we did not differentiate regular clinic visits from urgent care appointments, so the total number of clinic visits may have been overestimated. Secure messages may have been underestimated as only encounters visible in CPRS were counted. Secure messages can be completed without being saved into the EMR. Also, some veterans receive additional health care outside the VA. We were unable to account for health care utilization that took place at community health care systems or even other VA centers. We did not collect information on insurance or sociodemographic information. Data extraction of health care utilization was performed manually and could be susceptible to human error. Finally, given the retrospective nature of the study, we are unable to comment on causal effects.

\section{Conclusion}

Veterans on COT utilized significantly more ED visits, telephone triage, nurse visits, telephone calls, and secure messages compared with patients not on opioids, after adjusting for relevant diagnoses and other patient characteristics. While the PACT model has been effective in reducing utilization for other comorbidities, it did not decrease all utilization measures for patients on COT. This may just be an inevitable byproduct of a model designed to allow greater patient access. Regardless, effective management of patients on COT likely requires more than just primary care involvement. Multidisciplinary and interdisciplinary pain management programs have been shown to be beneficial. ${ }^{14,29}$ Their integration with primary care might be an area for future studies.

\section{Acknowledgments}

This research was presented as an oral presentation at the 2017 Society of General Internal Medicine Annual Meeting in Washington, DC. The information provided in this study does not represent the views of the Department of Veterans Affairs or the US Government.

This study was supported by the Advancing a Healthier Wisconsin - Patient-Centered Outcomes Research Program.

\section{Disclosure}

The authors report no conflicts of interest in this work.

\section{References}

1. Nahin RL. Estimates of pain prevalence and severity in adults: United States, 2012. J Pain. 2015;16(8):769-780.

2. Kazis LE, Miller DR, Clark J, et al. Health-related quality of life in patients served by the Department of Veterans Affairs: results from the Veterans Health Study. Arch Intern Med. 1998;158(6):626-632.

3. Agha Z, Lofgren RP, Vanruiswyk JV, Layde PM. Are patients at Veterans Affairs medical centers sicker? A comparative analysis of health status and medical resource use. Arch Intern Med. 2000;160(21):3252-3257.

4. Thompson D, Many U.S. Vets Suffer Chronic Pain, Take Narcotic Painkillers: Study [webpage on the Internet]. HealthDay; 2014 [cited May 2, 2016]. Available from: https://consumer.healthday.com/boneand-joint-information-4/pain-health-news-520/many-u-s-vets-sufferchronic-pain-take-narcotic-painkillers-study-689325.html. Accessed August 15, 2018.

5. Toblin RL, Quartana PJ, Riviere LA, Walper KC, Hoge CW. Chronic pain and opioid use in US soldiers after combat deployment. JAMA Intern Med. 2014;174(8):1400-1401.

6. Shipherd JC, Keyes M, Jovanovic T, et al. Veterans seeking treatment for posttraumatic stress disorder: what about comorbid chronic pain? J Rehabil Res Dev. 2007;44(2):153.

7. Kerns RD, Otis J, Rosenberg R, Reid MC. Veterans' reports of pain and associations with ratings of health, health-risk behaviors, affective distress, and use of the health care system. J Rehabil Res Dev. 2003;40(5):371.

8. Banks SM, Kerns RD. Explaining high rates of depression in chronic pain: a diathesis-stress framework. Psychol Bull. 1996;119(1):95-110.

9. Sareen J, Jacobi F, Cox BJ, Belik SL, Clara I, Stein MB. Disability and poor quality of life associated with comorbid anxiety disorders and physical conditions. Arch Intern Med. 2006;166(19):2109-2116.

10. Gureje O, Simon GE, von Korff M. A cross-national study of the course of persistent pain in primary care. Pain. 2001;92(1-2):195-200.

11. Patient Aligned Care Team (PACT) Handbook. Department of Veterans Affairs [webpage on the Internet]. Veterans Health Administration; 2014 [cited May 29, 2017]. Available from: https://www.va.gov/vhapublications/ViewPublication.asp?pub_ID=2977. Accessed August 8, 2018.

12. PACT Team-Based Care. The fourth component of PACT is the concept of team-based care [webpage on the Internet]. Department of Veterans Affairs; 2016 [cited May 29, 2017]. Available from: https://www. patientcare.va.gov/primarycare/pact/Team-Based.asp. Accessed August 15,2018

13. Rosland AM, Nelson K, Sun H, et al. The patient-centered medical home in the Veterans Health Administration. Am J Manag Care. 2013;19(7):e263-272.

14. Nelson KM, Helfrich C, Sun H, et al. Implementation of the patient-centered medical home in the Veterans Health Administration: associations with patient satisfaction, quality of care, staff burnout, and hospital and emergency department use. JAMA Intern Med. 2014;174(8):1350-1358.

15. Becker A, Held H, Redaelli M, et al. Low back pain in primary care: costs of care and prediction of future health care utilization. Spine. 2010;35(18):1714-1720.

16. Blyth FM, March LM, Brnabic AJ, Cousins MJ. Chronic pain and frequent use of health care. Pain. 2004;111(1-2):51-58. 
17. Lazkani A, Delespierre T, Bauduceau B, et al. Healthcare costs associated with elderly chronic pain patients in primary care. Eur J Clin Pharmacol. 2015;71(8):939-947.

18. National Institutes of Health Medline Plus (USA). Chronic pain symptoms, diagnosis, \& treatment [webpage on the Internet]. National Institutes of Health; 2011 [cited January 10, 2016]. Available from: https://www.nlm.nih.gov/medlineplus/magazine/issues/spring11/ articles/spring11pg5-6.html. Accessed August 15, 2018.

19. Elliott AM, Smith BH, Penny KI, Smith WC, Chambers WA. The epidemiology of chronic pain in the community. Lancet. 1999;354(9186): 1248-1252.

20. Chou R, Turner JA, Devine EB, et al. The effectiveness and risks of long-term opioid therapy for chronic pain: a systematic review for a National Institutes of Health Pathways to Prevention Workshop. Ann Intern Med. 2015;162(4):276-286.

21. Harris PA, Taylor R, Thielke R, Payne J, Gonzalez N, Conde JG. Research electronic data capture (REDCap) - a metadata-driven methodology and workflow process for providing translational research informatics support. J Biomed Inform. 2009;42(2):377-381.

22. Weimer M, Gideonse N, Mauer K, Stacey B. Guideline for safe chronic opioid therapy prescribing for patients with chronic non-cancer pain [webpage on the Internet]. Oregon Health \& Science University; 2013 [cited December 10, 2015]. Available from: http://www.oregonpainguidance.org/app/content/uploads/2015/04/OHSU_Opioid_Guideline_1-14. pdf. Accessed August 15, 2018.

23. von Korff M, Korff MV, Saunders K, Ray GT, et al. De facto long-term opioid therapy for noncancer pain. Clin J Pain. 2008;24(6):521-527.

24. Morasco BJ, Duckart JP, Carr TP, Deyo RA, Dobscha SK. Clinical characteristics of veterans prescribed high doses of opioid medications for chronic non-cancer pain. Pain. 2010;151(3):625-632.
25. Substance abuse. World Health Organization [webpage on the Internet]; 2018 [cited April 5, 2018]. Available from: http://www.who.int/topics/ substance_abuse/en/.

26. Dowell D, Haegerich TM, Chou R. CDC guideline for prescribing opioids for chronic pain - United States, 2016. JAMA. 2016;315(15): 1624-1645.

27. Beehler GP, Rodrigues AE, Mercurio-Riley D, Dunn AS. Primary care utilization among veterans with chronic musculoskeletal pain: a retrospective chart review. Pain Med. 2013;14(7):1021-1031.

28. Kay C, Wozniak E, Bernstein J. Utilization of health care services and ambulatory resources associated with chronic noncancer pain. Pain Med. 2017;18(7):1236-1246.

29. Randall I, Mohr DC, Maynard C. VHA patient-centered medical home associated with lower rate of hospitalizations and specialty care among veterans with posttraumatic stress disorder. J Healthc Qual. 2017;39(3):168-176.

30. Rutkow L, Chang HY, Daubresse M, Webster DW, Stuart EA, Alexander GC. Effect of Florida's prescription drug monitoring program and pill mill laws on opioid prescribing and use. JAMA Intern Med. 2015;175(10):1642-1649.

31. Johnson H, Paulozzi L, Porucznik C, Mack K, Herter B. Decline in drug overdose deaths after state policy changes - Florida, 2010-2012. MMWR Morb Mortal Wkly Rep. 2014;63(26):569-574.

32. Gatchel RJ, Okifuji A. Evidence-based scientific data documenting the treatment and cost-effectiveness of comprehensive pain programs for chronic nonmalignant pain. J Pain. 2006;7(11):779-793.

33. Flor H, Fydrich T, Turk DC. Efficacy of multidisciplinary pain treatment centers: a meta-analytic review. Pain. 1992;49(2):221-230. 


\section{Supplementary materials}

Table SI Multivariable ordinal logistic regression of variables associated with ED visits

\begin{tabular}{|c|c|c|}
\hline Variable & OR & $95 \% \mathrm{Cl}$ \\
\hline Pain $^{\mathrm{a}}$ & 1.864 & $1.426-2.439$ \\
\hline Age & 0.989 & $0.977-1.000$ \\
\hline Non-white race ${ }^{a}$ & 1.680 & $1.293-2.184$ \\
\hline Advance practitioner & 0.878 & $0.684-1.128$ \\
\hline Psychiatric diagnosis $^{a}$ & 1.932 & $1.404-2.663$ \\
\hline Depression & 0.906 & $0.674-1.216$ \\
\hline Diabetes & 1.291 & Iו \\
\hline Hypertension & 0.857 & $0.647-1.138$ \\
\hline CKD/ESRD & 1.370 & $0.888-2.096$ \\
\hline COPD/asthma ${ }^{a}$ & 1.500 & $1.093-2.052$ \\
\hline $\mathrm{CAD} / \mathrm{CHF}^{\mathrm{a}}$ & 1.523 & $1.117-2.073$ \\
\hline Neuropathy & 1.266 & $0.860-|.85|$ \\
\hline Obesity & 0.918 & $0.710-1.186$ \\
\hline History of substance abuse & 1.175 & $0.839-1.637$ \\
\hline Tobacco use & 0.800 & $0.604-1.055$ \\
\hline Arthritis/spinal stenosis & 0.973 & $0.748-1.265$ \\
\hline NSAID use & 0.989 & $0.713-1.365$ \\
\hline Antiepileptic use ${ }^{a}$ & 1.614 & $1.181-2.202$ \\
\hline Benzodiazepine use & 0.993 & $0.648-1.507$ \\
\hline Service connection & 0.799 & $0.619-1.030$ \\
\hline
\end{tabular}

Notes: Full model with significant independent variables are shown. ${ }^{\text {aSignificant }}$ variable.

Abbreviations: ED, emergency department; CKD, chronic kidney disease; ESRD, end-stage renal disease; COPD, chronic obstructive pulmonary disease; CAD, coronary artery disease; CHF, congestive heart failure; NSAID, nonsteroidal antiinflammatory drug.

Table S2 Multivariable logistic regression of variables associated with hospitalization

\begin{tabular}{|c|c|c|}
\hline$\overline{\text { Variable }}$ & OR & $95 \% \mathrm{Cl}$ \\
\hline Pain & 1.343 & $0.936-1.936$ \\
\hline Age & 1.008 & $0.992-1.025$ \\
\hline Non-white race & 1.254 & $0.877-1.784$ \\
\hline Advance practitioner & 0.986 & $0.700-1.384$ \\
\hline Psychiatric diagnosis $^{\mathrm{a}}$ & 1.754 & $|| 22-2.75 \mid$. \\
\hline Depression & 1.072 & $0.724-1.591$ \\
\hline Diabetes & $1.26 \mathrm{I}$ & $0.875-1.813$ \\
\hline Hypertension & 1.083 & $0.737-1.609$ \\
\hline CKD/ESRD & 1.884 & $1.138-3.07 \mid$ \\
\hline COPD/asthma & 1.346 & $0.89 \mid-2.002$ \\
\hline $\mathrm{CAD} / \mathrm{CHF}^{\mathrm{a}}$ & 1.944 & $1.326-2.843$ \\
\hline Neuropathy ${ }^{\mathrm{a}}$ & 1.652 & $1.034-2.595$ \\
\hline Obesity & 0.683 & $0.477-0.971$ \\
\hline History of substance abuse & $\mathrm{I} .484$ & $0.959-2.266$ \\
\hline Tobacco use & 1.103 & $0.759-1.590$ \\
\hline Arthritis/spinal stenosis & 0.925 & $0.650-1.308$ \\
\hline NSAID use & 0.793 & $0.487-1.256$ \\
\hline Antiepileptic use $\mathrm{a}^{\mathrm{a}}$ & 1.587 & $1.060-2.357$ \\
\hline Benzodiazepine use & 1.402 & $0.819-2.337$ \\
\hline Service connection ${ }^{\mathrm{a}}$ & 0.701 & $0.499-0.981$ \\
\hline
\end{tabular}

Notes: Full model with significant independent variables are shown. ${ }^{\text {aSignificant }}$ variable.

Abbreviations: CKD, chronic kidney disease; ESRD, end-stage renal disease; COPD, chronic obstructive pulmonary disease; CAD, coronary artery disease; CHF, congestive heart failure; NSAID, nonsteroidal anti-inflammatory drug.
Table S3 Multivariable ordinal logistic regression of variables associated with clinic visits

\begin{tabular}{|c|c|c|}
\hline Variable & OR & $95 \% \mathrm{Cl}$ \\
\hline Pain & 1.204 & $0.935-1.552$ \\
\hline Age & 1.006 & $0.995-1.017$ \\
\hline Non-white race & $\mathrm{I} .144$ & $0.889-1.474$ \\
\hline Advance practitioner ${ }^{\mathrm{a}}$ & 0.689 & $0.543-0.874$ \\
\hline Psychiatric diagnosis ${ }^{\mathrm{a}}$ & 1.890 & $1.400-2.557$ \\
\hline Depression & 1.073 & $0.798-|.44|$ \\
\hline Diabetes $^{\mathrm{a}}$ & 1.468 & $1.125-1.917$ \\
\hline Hypertension & 1.270 & $0.968-1.667$ \\
\hline CKD/ESRD ${ }^{a}$ & 1.764 & $1.17 \mid-2.663$ \\
\hline COPD/asthma ${ }^{a}$ & 1.633 & $1.200-2.227$ \\
\hline $\mathrm{CAD} / \mathrm{CHF}$ & 1.319 & $0.980-1.777$ \\
\hline Neuropathy & 1.302 & $0.900-1.885$ \\
\hline Obesity & 1.096 & $0.862-1.396$ \\
\hline History of substance abuse & 1.083 & $0.779-1.508$ \\
\hline Tobacco use & 0.894 & $0.687-1.164$ \\
\hline Arthritis/spinal stenosis & 1.092 & $0.850-1.403$ \\
\hline NSAID use $\mathrm{e}^{\mathrm{a}}$ & 1.439 & $1.047-1.980$ \\
\hline Antiepileptic use ${ }^{\mathrm{a}}$ & 1.548 & $1.133-2.116$ \\
\hline Benzodiazepine use $\mathrm{e}^{\mathrm{a}}$ & 1.629 & $|.075-2.47|$ \\
\hline Service connection & 0.943 & $0.742-1.198$ \\
\hline
\end{tabular}

Notes: Full model with significant independent variables are shown. ${ }^{\text {aSignificant }}$ variable.

Abbreviations: CKD, chronic kidney disease; ESRD, end-stage renal disease; COPD, chronic obstructive pulmonary disease; CAD, coronary artery disease; $\mathrm{CHF}$, congestive heart failure; NSAID, nonsteroidal anti-inflammatory drug.

Table S4 Multivariable logistic regression of variables associated with telephone triage

\begin{tabular}{|c|c|c|}
\hline Variable & OR & $95 \% \mathrm{Cl}$ \\
\hline Pain $^{\mathrm{a}}$ & $\mathrm{I} .402$ & $1.043-1.888$ \\
\hline $\mathrm{Age}^{\mathrm{a}}$ & 0.984 & $0.972-0.997$ \\
\hline Non-white race & I.I74 & $0.876-1.57 \mid$ \\
\hline Advance practitioner & 0.889 & $0.673-1.173$ \\
\hline Psychiatric diagnosis $^{\mathrm{a}}$ & 1.696 & $1.192-2.418$ \\
\hline Depression & 0.902 & $0.652-1.248$ \\
\hline Diabetes & 1.063 & $0.778-1.449$ \\
\hline Hypertension & I. 127 & $0.824-1.548$ \\
\hline CKD/ESRD & 1.063 & $0.652-1.697$ \\
\hline COPD/asthma & 1.220 & $0.857-1.722$ \\
\hline $\mathrm{CAD} / \mathrm{CHF}$ & 1.371 & $0.972-1.928$ \\
\hline Neuropathy & 1.031 & $0.669-1.565$ \\
\hline Obesity $^{a}$ & 0.752 & $0.564-0.999$ \\
\hline History of substance abuse & 0.988 & $0.675-1.433$ \\
\hline Tobacco use & 0.841 & $0.616-1.141$ \\
\hline Arthritis/spinal stenosis & 0.935 & $0.698-1.249$ \\
\hline NSAID use & 1.352 & $0.950-1.914$ \\
\hline Antiepileptic use $\mathrm{a}^{\mathrm{a}}$ & 1.526 & $1.082-2.144$ \\
\hline Benzodiazepine use & 1.439 & $0.916-2.240$ \\
\hline Service connection & 0.813 & $0.6 \mid 4-1.076$ \\
\hline
\end{tabular}

Notes: Full model with significant independent variables are shown. ${ }^{a}$ Significant variable.

Abbreviations: CKD, chronic kidney disease; ESRD, end-stage renal disease; COPD, chronic obstructive pulmonary disease; $C A D$, coronary artery disease; $C H F$, congestive heart failure; NSAID, nonsteroidal anti-inflammatory drug. 
Table S5 Multivariable ordinal logistic regression of variables associated with telephone calls/secure messages

\begin{tabular}{|c|c|c|}
\hline Variable & OR & $95 \% \mathrm{Cl}$ \\
\hline Pain $^{\mathrm{a}}$ & 1.554 & $1.198-2.018$ \\
\hline Age & 1.002 & $0.991-1.014$ \\
\hline Non-white race & 1.259 & $0.972-1.629$ \\
\hline Advance practitioner ${ }^{\mathrm{a}}$ & 0.691 & $0.54 I-0.88 I$ \\
\hline Psychiatric diagnosis $^{\mathrm{a}}$ & 1.566 & $1.150-2.132$ \\
\hline Depression & 0.833 & $0.621-1.117$ \\
\hline Diabetes $^{\mathrm{a}}$ & 1.835 & $\mathrm{I} .404-2.40 \mathrm{I}$ \\
\hline Hypertension & 1.031 & $0.784-1.358$ \\
\hline CKD/ESRD & 1.193 & $0.797-1.776$ \\
\hline COPD/asthma & 1.087 & $0.794-1.480$ \\
\hline $\mathrm{CAD} / \mathrm{CHF}$ & 1.259 & $0.935-1.691$ \\
\hline Neuropathy & 1.406 & $0.972-2.025$ \\
\hline Obesity & 0.799 & $0.621-1.026$ \\
\hline History of substance abuse & 0.875 & $0.617-1.232$ \\
\hline Tobacco use & 0.774 & $0.586-1.017$ \\
\hline Arthritis/spinal stenosis & 1.188 & $0.921-1.531$ \\
\hline NSAID use & 1.287 & $0.937-1.761$ \\
\hline Antiepileptic use ${ }^{a}$ & 1.482 & $1.092-2.005$ \\
\hline Benzodiazepine use & I. 187 & $0.781-1.795$ \\
\hline Service connection & 1.173 & $0.918-1.498$ \\
\hline
\end{tabular}

Notes: Full model with significant independent variables are shown. ${ }^{a}$ Significant variable.

Abbreviations: CKD, chronic kidney disease; ESRD, end-stage renal disease; COPD, chronic obstructive pulmonary disease; $C A D$, coronary artery disease; $\mathrm{CHF}$, congestive heart failure; NSAID, nonsteroidal anti-inflammatory drug.

\section{Publish your work in this journal}

The Journal of Pain Research is an international, peer reviewed, open access, online journal that welcomes laboratory and clinical findings in the fields of pain research and the prevention and management of pain. Original research, reviews, symposium reports, hypothesis formation and commentaries are all considered for publication.

\section{Dovepress}

The manuscript management system is completely online and includes a very quick and fair peer-review system, which is all easy to use. Visit http://www.dovepress.com/testimonials.php to read real quotes from published authors. 